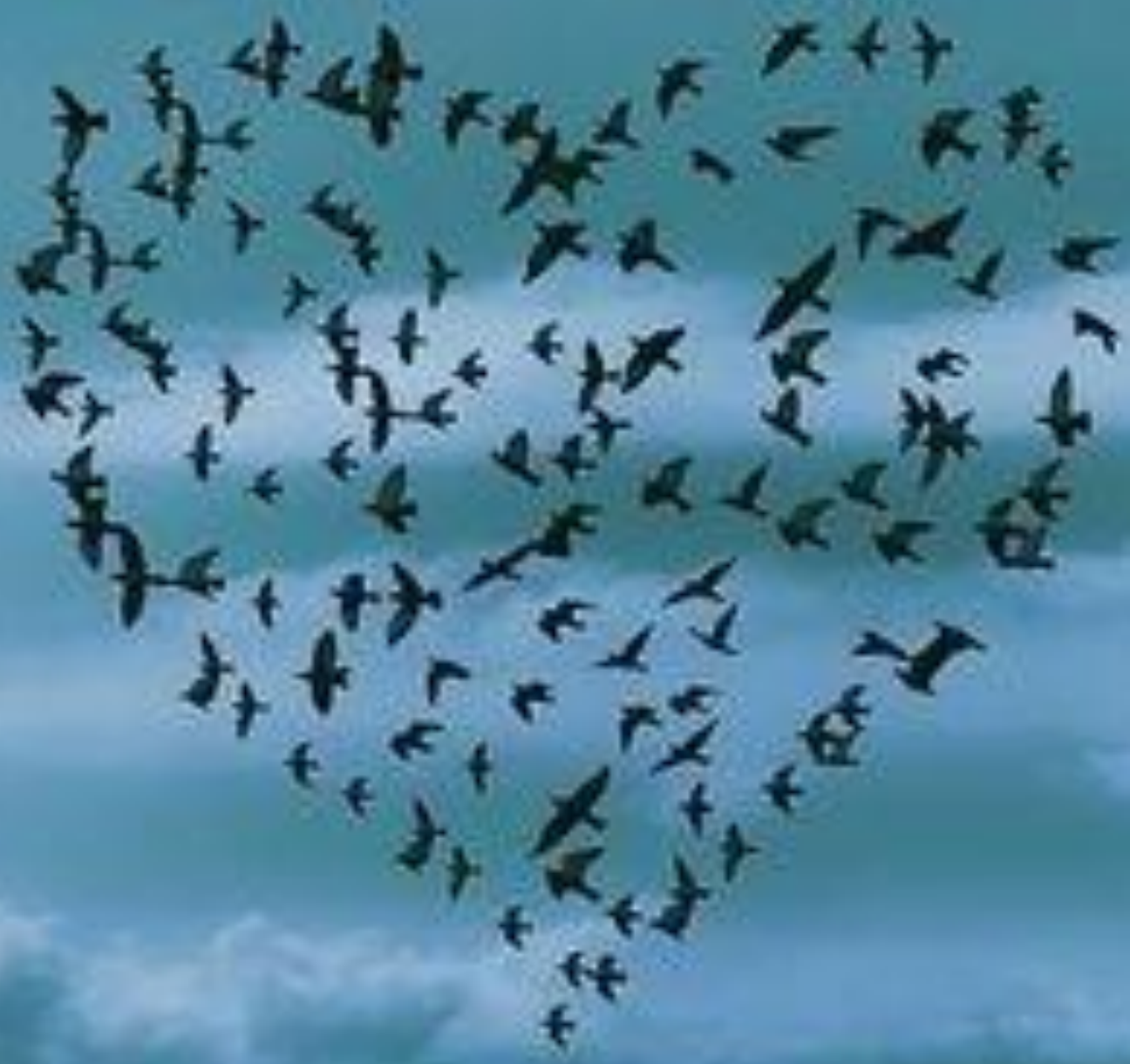

Study to Assess Knowledge and Attitude Regarding Self Care Among Patients Undergoing Hemodialysis in Selected Hospital of Punjab, India

Bhuvanesh Shulda Amandeep Kaur 


\section{Study to Assess \\ Knowledge and Attitude Regarding Self Care \\ Among Patients Undergoing Hemodialysis in Selected Hospital of Punjab, India} Bhuvanesh Shukla, Amandeep Kaur 


\section{Study to Assess Knowledge and Attitude Regarding Self Care among Patients Undergoing Hemodialysis in Selected Hospital of Punjab, India}

\section{Abstract}

Self-care is the performance or practice of activities that individuals initiate and perform to maintain life, health, and well being. Hemodialysis patients must be able to perform self-care tasks in order to prevent complications and live life productively. A descriptive study to assess knowledge and attitude regarding self care among patients undergoing Hemodialysis in selected hospital, Punjab was done. The study was conducted on the patients from the dialysis unit of the Patel Hospital, Jalandhar, Punjab immediately above the abstract; it sets the footnote at the bottom of this column.

\section{Index Terms - Hemodialysis, Knowledge, Attitude, Self-Care}

\section{Introduction}

Kidneys are the vital organ of our body and are integral to maintain the body's homeostasis. The kidneys produce and secrete hormones and enzymes that help to regulate red blood cell production, blood pressure and calcium and phosphate metabolism. By excreting metabolic end products and varying the excretion of water and solutes, the kidneys regulate body fluid volume, acidity and electrolytes, thus maintaining normal body composition.

Chronic Renal Failure (CRF) is a progressive deterioration of kidney function in which the body metabolism and water and electrolyte balance would be disturbed resulting in uremia. The burden of chronic disease on health care services worldwide is growing and the increased development of educational interventions which help patients to better manage their conditions is evident internationally. Such development has been promoted by health policies as patients have to understand and manage their conditions more on their own in order to reduce health services costs.

As estimated, about one lakh patients suffer from chronic kidney disorders in India and only $20 \%$ can afford the treatment. Annually only 3000 transplants are conducted and 7000 patients take dialysis. By 2015, chronic kidney disorders and cardiovascular diseases arising out of hypertension would result in 36 million fatalities. Globally over 1.5 million chronic kidney 
disorders cases survive with either hemo or peritoneal dialysis or transplantation. The number of cases is expected to double within the next decade. The global dialysis market could grow in excess of $\$ 73$ billion by 2011 due to an increasing population of kidney disease patients, according to a report.

Hemodialysis has a therapeutic effect on end stage renal disease (ESRD), but these patients encounter many physical, psychological, social stress, many pathological states such as hypertension, lack of appetite, anemia, genital disorder such as change in menstruation, skin disorders such as itching, change in skin color and arteriovenous fistula. Self-care is the performance or practice of activities that individuals initiate and perform to maintain life, health, and well being. When self-care is effectively performed, it helps to maintain structural integrity and human functioning. Hemodialysis patients must be able to perform self-care tasks in order to prevent complications and live life productively. Self care activities are influenced by the knowledge and attitude regarding self care among patients undergoing Hemodialysis. During the clinical posting the investigator observed that patient undergoing Hemodialysis lack self care abilities due to lack of knowledge. Therefore the investigator felt the need for this research project and undertook this study.

\section{Statement of the problem}

"A descriptive study to assess knowledge and attitude regarding self care among patients undergoing Hemodialysis in selected hospital, Punjab"

\section{Purpose}

The purpose of the study is to assess knowledge and attitude regarding self care among patients undergoing Hemodialysis.

\section{Objectives of the study}

1. To assess knowledge regarding self care among patients undergoing Hemodialysis.

2. To assess attitude regarding self care among patients undergoing Hemodialysis.

3. To find out the correlation between knowledge and attitude regarding self care among patients undergoing Hemodialysis.

4. To find out the relationship of knowledge regarding self care with selected variables such as age, gender, education, occupation, family income, marital status, type of family, residential area, duration of illness. 
5. To find out the relationship of attitude regarding self care with selected variables such as age, gender, education, occupation, family income, marital status, type of family, residential area, duration of illness.

6. To develop guidelines regarding self care for patients undergoing Hemodialysis.

\section{Assumption}

Patients undergoing Hemodialysis have little knowledge and negative attitude regarding self care.

\section{Operational definitions}

1. Knowledge: It refers to Hemodialysis patient's range of factual information regarding self care as evident from their knowledge score.

2. Attitude: It refers to the set of beliefs showing mental predisposition towards self care among patients undergoing Hemodialysis.

3. Self care: It refers to the activities required to be performed by Hemodialysis patients to optimize health and prevent complications.

\section{Delimitations}

1. The study was delimited to patients undergoing Hemodialysis for at least 3 months.

2. Patients of age 18 years or more were selected in the sample.

\section{Research approach and design}

Quantitative non experimental approach was used for the study to accomplish the objectives of the study. Descriptive research design has been used to achieve the objectives of the study.

\section{Independent variables}

In this study, the independent variables are age, gender, education, occupation, family income, marital status, type of family, residential area, duration of illness of patients undergoing Hemodialysis.

\section{Dependent variables}

In this study, dependent variables are knowledge and attitude regarding self care among patients undergoing Hemodialysis. 


\section{Setting}

The study was conducted in the dialysis unit of Patel hospital, Jalandhar, Punjab. Patel hospital is 150 bedded multi-specialty and super-specialty hospital in Jalandhar, equipped with ultra modern and state of the art facilities for comprehensive care right from OPD consultations and routine health check-ups to Intensive Care and super-specialized surgeries. The reason for selecting this hospital was investigator's convenience and expected cooperation from the authorities in getting permission for conducting the study.

\section{Target population}

The target population consists of patients undergoing Hemodialysis at selected hospital, Punjab.

\section{Sample and sample size}

It consists of 44 patients undergoing Hemodialysis.

\section{Sampling technique}

Purposive sampling technique was employed in the selection of sample based on inclusion and exclusion criteria.

\section{Criteria for sample selection}

- Inclusion criteria

○ The study was limited to patients who were:

- Undergoing Hemodialysis for at least 3 months.

- Of age 18 years or more and of either sex.

- Willing to participate in the study.

- Exclusion criteria

- Patients who were critically ill were excluded from responding

\section{Findings}

The findings showed that $25 \%$ of patients had excellent knowledge regarding self care followed by $22.73 \%$ of patients had below average knowledge. It was also confirmed that most of the patients undergoing Hemodialysis i.e. $63.64 \%$ have moderately positive attitude towards self care followed by $36.36 \%$ of patients having highly positive attitude towards self care. It was confirmed that there exists a moderately positive correlation between knowledge and attitude i.e. with the increase in knowledge there will be positive attitude of patients regarding self care. It was also confirmed that a significant relationship exists between duration of illness and 
knowledge of patient regarding self care. There was no significant relationship between other demographic variables and knowledge regarding self care among patients undergoing Hemodialysis. There was no significant relationship between demographic variables and attitude regarding self care among patients undergoing Hemodialysis.

\section{Conclusion}

The study revealed that only $25 \%$ of the patients undergoing Hemodialysis had excellent knowledge and $25 \%$ had average and $22.73 \%$ had below average knowledge regarding self care and majority of the patients undergoing Hemodialysis had moderately positive attitude towards self care. Thus, chronic kidney disease (CKD) patients should be given certain guidelines regarding self care and should be counseled regularly at each visit while receiving Hemodialysis.

\section{Implications}

The findings of the study have several implications in nursing education, nursing practice, nursing administration, nursing research:-

\section{- Nursing education}

$\bigcirc$ Teaching self care to the patients suffering from chronic diseases is very important. Making patients to participate in their own care is the duty of nurses because chronic kidney disease patients undergoing Hemodialysis are at risk of developing many complications. Nursing curriculum should provide opportunities for students to improve their knowledge regarding health education required by these patients to prevent complications.

- Seminars, workshops, conferences should be organized in nursing institutions to improve the knowledge of nursing students regarding self care among patients undergoing Hemodialysis.

\section{- Nursing Practice}

○ Nursing professionals working in dialysis unit should teach and improve knowledge on self care among clients undergoing Hemodialysis.

- Nurses should place health in the client hands, especially for the chronic kidney disease clients, since they have to undergo lifelong dialysis. The guidelines developed by the investigator can be used by nurses to educate the chronic kidney patients undergoing Hemodialysis. 


\section{- Nursing Administration}

- Nursing administrators should make provision for in-service education and continuing education for nurses.

- Nursing administrators can start structured teaching program about the self care and to provide counseling and psychological support to such patients, on regular basis in Hemodialysis patient teaching section.

- Nursing administrators should ensure that nurses working in dialysis are adequately equipped with knowledge and skill to educate patients regarding self care.

\section{- Nursing Research}

- Research should be directed for exploring and updating the knowledge of nurses regarding self care needs among patients undergoing Hemodialysis.

- Nursing research should be conducted to prepare standard patient education material for chronic kidney disease patients. The present study serves to produce patient education material on self care among patients undergoing Hemodialysis.

o The study also helps the nurse researchers to develop awareness into the knowledge and attitude of the patients undergoing Hemodialysis regarding self care among them and hence can be utilized in preparing nursing intervention related to promotion of health and prevention of complications among these patients.

\section{Recommendations}

The following recommendations are made on the basis of the findings of the present study:

- A similar study may be replicated on a large sample to validate and generalize the findings.

- An exploratory study may be carried out to assess knowledge and practice regarding self care among patients undergoing Hemodialysis.

- An exploratory study on quality of life among patients undergoing Hemodialysis with and without selfefficacy should be conducted.

- Methodological study can be conducted to standardize the present tool. 
- Longitudinal study should be undertaken to assess the effectiveness of different self care strategies in preventing complications among patients undergoing Hemodialysis.

\section{References}

1. Phipps, Monahan, Sands, Marek, Neighors. Medical Surgical Nursing Health and Illness perspectives. 7th ed. Missouri: Mosby; 2003. 1186.

2. Mehdi Heidarzadeh, Solmaz Atashpeikar, Tahereh Jalilazar. Relationship between Quality of life and self care ability in patients receiving Hemodialysis. IJNMR. 2010 Jan; 15 (2): 66-71

3. Berzins K, Reilly S, Abell J, Hughes J \& Challis D. UK self-care support initiatives for older patients with long-term conditions. Chronic Illn. 2009; 5, 2009. 56-72.

4. Eskridge MS. Hypertension and chronic kidney disease: the role of lifestyle modification and medication management. Nephrol Nurs J. 2010 Jan-Feb; 37(1): 55-60, 99. 


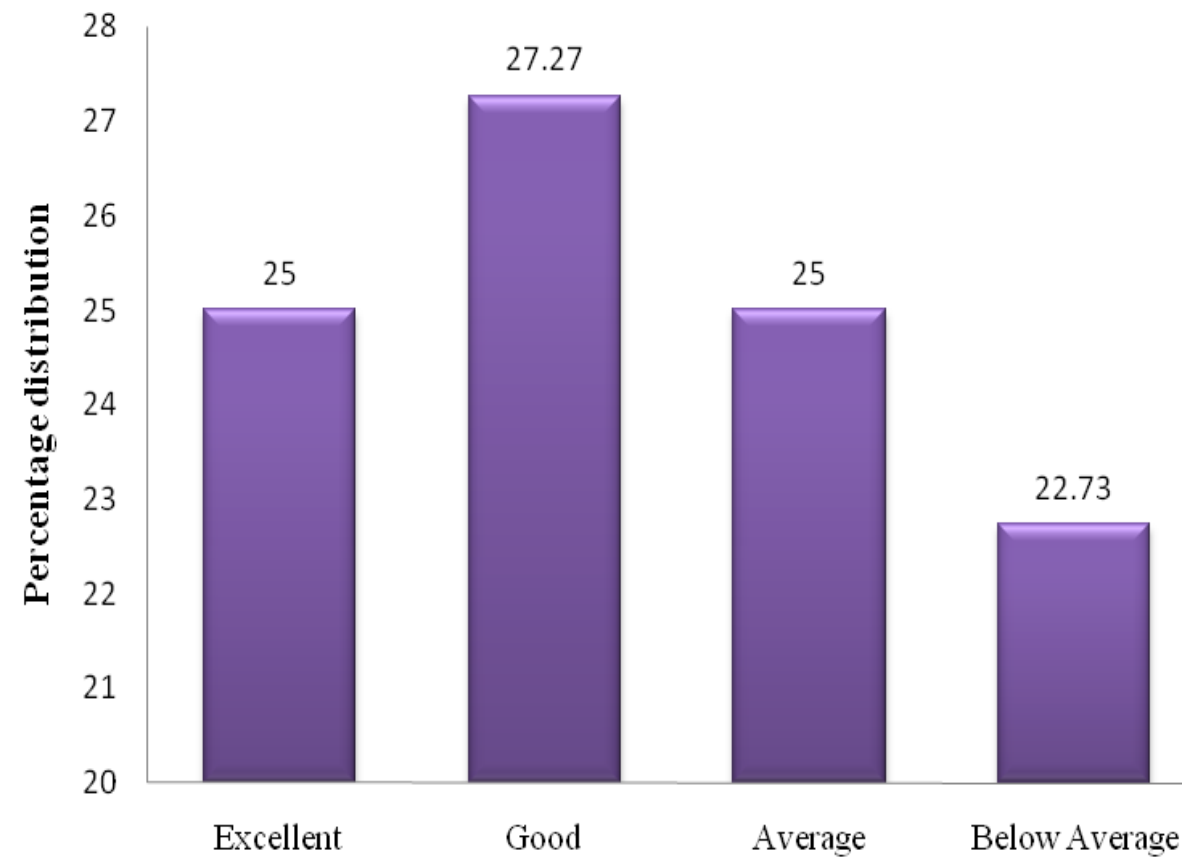

Level of knowledge

Figure 1: Percentage distribution of patients undergoing Hemodialysis according to level of knowledge regarding self care.

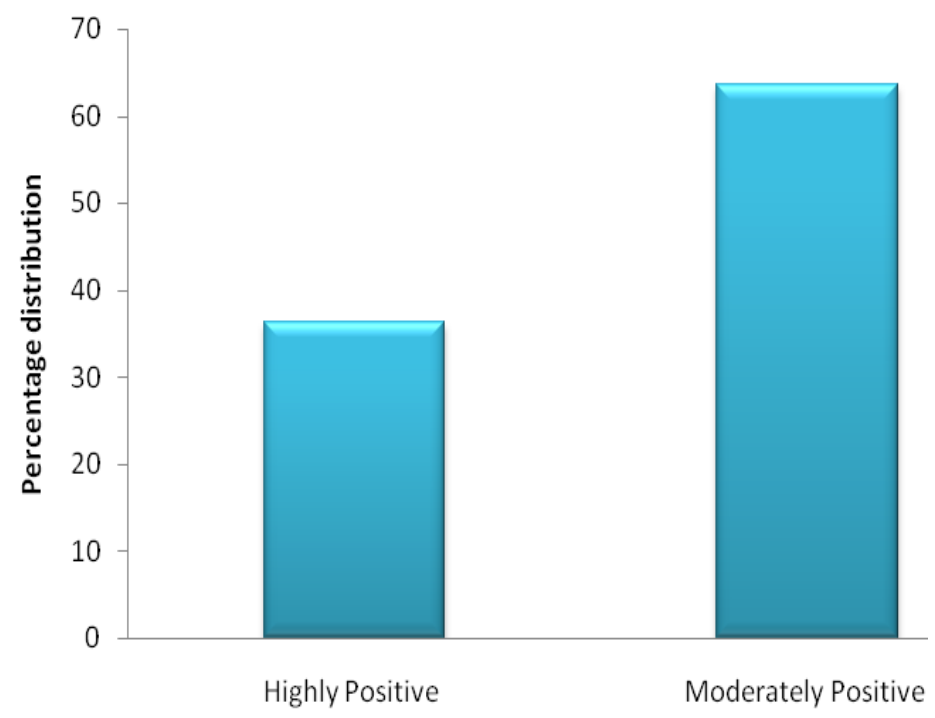

Level of attitude

Figure 2: Percentage distribution of patients undergoing hemodialysis according to level of attitude regarding self care 
Table 1: Frequency and percentage distribution of sample characteristic

\begin{tabular}{|c|c|c|}
\hline & & $N=44$ \\
\hline Demographic variable & $\mathbf{N}$ & $\%$ \\
\hline \multicolumn{3}{|c|}{ Age (years) } \\
\hline$<20$ & 1 & 2.27 \\
\hline $21-30$ & 3 & 6.82 \\
\hline $31-40$ & 6 & 13.64 \\
\hline above 40 & 34 & 77.27 \\
\hline \multicolumn{3}{|c|}{ Gender } \\
\hline Male & 32 & 72.73 \\
\hline Female & 12 & 27.27 \\
\hline \multicolumn{3}{|c|}{ Education } \\
\hline Below Matric & 9 & 20.46 \\
\hline Matric & 9 & 20.46 \\
\hline Senior Secondary & 7 & 15.90 \\
\hline Graduation and above & 19 & 43.18 \\
\hline \multicolumn{3}{|c|}{ Occupation } \\
\hline Govt. job & 15 & 34.09 \\
\hline Private job & 15 & 34.09 \\
\hline Farmer/Labourer & 4 & 9.09 \\
\hline Unemployed/housewife & 10 & 22.73 \\
\hline \multicolumn{3}{|c|}{ Family Income (Rs/month) } \\
\hline Less than 5000 & 10 & 22.73 \\
\hline $5001-10,000$ & 8 & 18.18 \\
\hline $10,001-20,000$ & 14 & 31.81 \\
\hline More than 20,000 & 12 & 27.27 \\
\hline \multicolumn{3}{|c|}{ Marital Status } \\
\hline Married & 37 & 84.09 \\
\hline Single & 7 & 15.91 \\
\hline \multicolumn{3}{|c|}{ Type of family } \\
\hline Joint & 25 & 56.82 \\
\hline Nuclear & 19 & 43.18 \\
\hline \multicolumn{3}{|l|}{ Residential area } \\
\hline Urban & 25 & 56.82 \\
\hline Rural & 19 & 43.18 \\
\hline \multicolumn{3}{|l|}{ Duration of illness } \\
\hline 3 months & 2 & 4.55 \\
\hline 6 months & 4 & 9.09 \\
\hline 1 year & 4 & 9.09 \\
\hline More than 1 year & 34 & 77.27 \\
\hline
\end{tabular}


Table 2: Frequency and percentage distribution of patients undergoing Hemodialysis according to level of knowledge regarding self care

\begin{tabular}{|l|c|c|c|}
\hline Level of knowledge & Criterion measure & $\mathbf{n}$ & \% \\
\hline Excellent & $\geq 76 \%$ & 11 & 25 \\
\hline Good & $61-75 \%$ & 12 & 27.27 \\
\hline Average & $51-60 \%$ & 11 & 25 \\
\hline Below average & $\leq 50 \%$ & 10 & 22.73 \\
\hline
\end{tabular}

Maximum Score $=22$

Minimum Score $=0$

Table 3: Correlation of mean knowledge score and mean attitude score regarding self care among patients undergoing Hemodialysis $(\mathbf{N}=\mathbf{4 4})$

\begin{tabular}{|l|c|c|c|}
\hline Variable & Correlation maximum score & Mean & R \\
\hline & & & \\
\hline Knowledge & 22 & 14.29 & \\
\hline Attitude & 110 & 79.18 & 0.3 \\
\hline
\end{tabular}


Table 4: Mean knowledge score regarding self care among patients undergoing Hemodialysis according to selected variables $(\mathrm{N}=44)$

\begin{tabular}{|c|c|c|c|c|c|}
\hline \multirow{2}{*}{$\begin{array}{l}\text { Sample } \\
\text { characteristics }\end{array}$} & \multicolumn{5}{|c|}{ Knowledge Score } \\
\hline & $\mathbf{N \%}$ & Mean & SD & df & Test value \\
\hline \multicolumn{6}{|c|}{ Age (years) } \\
\hline Below 20 & $1(2.27)$ & 10 & & & \\
\hline $21-30$ & $3(6.82)$ & 14.66 & 2.3 & 3,40 & $\mathrm{~F}=.497^{\mathrm{NS}}$ \\
\hline $31-40$ & $6(13.64)$ & 14.83 & 2.48 & & \\
\hline Above 40 & $34(77.27)$ & 14.2 & 3.78 & & \\
\hline \multicolumn{6}{|c|}{ Gender } \\
\hline Male & $32(72.73)$ & 14.31 & 3.17 & & \\
\hline Female & $12(27.27)$ & 14.25 & 4.49 & 42 & $\mathrm{t}=.052^{\mathrm{NS}}$ \\
\hline \multicolumn{6}{|c|}{ Education } \\
\hline Primary & $9(20.46)$ & 15.22 & 2.63 & & \\
\hline Matric & $9(20.46)$ & 12.44 & 4.09 & 3,40 & $\mathrm{~F}=.591^{\mathrm{NS}}$ \\
\hline Senior Secondary & $7(15.90)$ & 16.28 & 1.7 & & \\
\hline $\begin{array}{l}\text { Graduation \& } \\
\text { above }\end{array}$ & $19(43.18)$ & 14 & 3.8 & & \\
\hline \multicolumn{6}{|c|}{ Occupation } \\
\hline Govt. Job & $15(34.09)$ & 14.66 & 3.79 & & \\
\hline Private Job & $15(34.09)$ & 15.26 & 2.68 & 3,40 & $\mathrm{~F}=2.550^{\mathrm{NS}}$ \\
\hline Farmer/Labourer & $4(9.09)$ & 10 & 4.08 & & \\
\hline $\begin{array}{l}\text { Unemployed/ } \\
\text { housewife }\end{array}$ & $10(22.73)$ & 14 & 3.19 & & \\
\hline \multicolumn{6}{|c|}{ Family income (Rs./ month) } \\
\hline Less than 5000 & $10(22.73)$ & 12 & 3.56 & & \\
\hline $5001-10,000$ & $8(18.18)$ & 13.12 & 3.48 & 3,40 & $\mathrm{~F}=3.211^{\mathrm{NS}}$ \\
\hline $10,001-20,000$ & $14(31.81)$ & 15.5 & 3.1 & & \\
\hline More than 20,000 & $12(27.27)$ & 15.58 & 3.12 & & \\
\hline \multicolumn{6}{|c|}{ Marital status } \\
\hline Married & $37(84.09)$ & 14.13 & 3.6 & & \\
\hline Single & $7(15.91)$ & 15.14 & 3.18 & 42 & $t=0.689^{N S}$ \\
\hline \multicolumn{6}{|c|}{ Type of family } \\
\hline Joint & $25(56.82)$ & 14.96 & 3.48 & & \\
\hline Nuclear & $19(43.18)$ & 13.42 & 3.48 & 42 & $\mathrm{t}=1.452^{\mathrm{NS}}$ \\
\hline \multicolumn{6}{|c|}{ Residential area } \\
\hline Urban & $25(56.82)$ & 15.2 & 3.62 & & \\
\hline Rural & $19(43.18)$ & 13.1 & 3.1 & 42 & $\mathrm{t}=2.02^{\mathrm{NS}}$ \\
\hline \multicolumn{6}{|c|}{ Duration of illness } \\
\hline 3 months & $2(4.55)$ & 13 & 1.41 & & \\
\hline 6 months & $4(9.09)$ & 8 & 3.65 & 3,40 & $\mathrm{~F}=7.991^{* *}$ \\
\hline 1 year & $4(9.09)$ & 13 & 3.37 & & \\
\hline more than 1year & $34(77.27)$ & 15.26 & 2.79 & & \\
\hline
\end{tabular}


ISSN 1839-6518

Table 5: Mean attitude score regarding self care among patients undergoing Hemodialysis according to selected variables $(\mathrm{N}=44)$

\begin{tabular}{|c|c|c|c|c|c|}
\hline \multirow[t]{2}{*}{ Sample characteristics } & \multicolumn{5}{|c|}{ Attitude score } \\
\hline & $\mathrm{n}(\%)$ & mear & SD & df & test value \\
\hline \multicolumn{6}{|c|}{ Age (years) } \\
\hline Below 20 & $1(2.27)$ & 88 & & & \\
\hline $21-30$ & $3(6.82)$ & 90.33 & 3.78 & 3,40 & $\mathrm{~F}=2.247^{\mathrm{Ns}}$ \\
\hline $31-40$ & $6(13.64)$ & 78.5 & 9.25 & & \\
\hline Above 40 & $34(77.27)$ & 78.05 & 8.92 & & \\
\hline \multicolumn{6}{|c|}{ Gender } \\
\hline Male & $32(72.73)$ & 79.81 & 8.98 & & \\
\hline Female & $12(27.27)$ & 77.5 & 9.69 & 42 & $\mathrm{t}=0.745^{\mathrm{NS}}$ \\
\hline \multicolumn{6}{|c|}{ Education } \\
\hline Primary & $9(20.46)$ & 75.55 & 9.79 & & \\
\hline Matric & $9(20.46)$ & 75.44 & 7 & 3,40 & $\mathrm{~F}=3.994^{\mathrm{Ns}}$ \\
\hline Senior Secondary & $7(15.90)$ & 88.71 & 8.36 & & \\
\hline Graduation \& above & $19(43.18)$ & 79.16 & 7.88 & & \\
\hline \multicolumn{6}{|c|}{ Occupation } \\
\hline Govt. Job & $15(34.09)$ & 79.87 & 8.23 & & \\
\hline Private Job & $15(34.09)$ & 81.27 & 8.58 & 3,40 & $\mathrm{~F}=.633^{\mathrm{NS}}$ \\
\hline Farmer/Labourer & $4(9.09)$ & 73.75 & 12.28 & & \\
\hline Unemployed/ housewife & $10(22.73)$ & 77.2 & 10.09 & & \\
\hline \multicolumn{6}{|c|}{ Family income per month (Rs.) } \\
\hline Less than 5000 & $10(22.73)$ & 77.4 & 11.02 & & \\
\hline $5001-10,000$ & $8(18.18)$ & 79.37 & 5.5 & 3,40 & $\mathrm{~F}=.200^{\mathrm{NS}}$ \\
\hline $10,001-20,000$ & $14(31.81)$ & 79.21 & 8.4 & & \\
\hline More than 20,000 & $12(27.27)$ & 80.5 & 10.88 & & \\
\hline \multicolumn{6}{|c|}{ Marital status } \\
\hline Married & $37(84.09)$ & 78.56 & 9.06 & & \\
\hline Single & $7(15.91)$ & 82.43 & 9.44 & 42 & $\mathrm{t}=1.028^{\mathrm{NS}}$ \\
\hline \multicolumn{6}{|c|}{ Type of family } \\
\hline Joint & $25(56.82)$ & 81.12 & 8 & & \\
\hline Nuclear & $19(43.18)$ & 76.63 & 10.06 & 42 & $\mathrm{t}=1.649^{\mathrm{NS}}$ \\
\hline \multicolumn{6}{|c|}{ Residential area } \\
\hline Urban & $25(56.82)$ & 79.48 & 9.6 & & \\
\hline Rural & $19(43.18)$ & 78.79 & 8.68 & 42 & $\mathrm{t}=0.246^{\mathrm{NS}}$ \\
\hline \multicolumn{6}{|c|}{ Duration of illness } \\
\hline 3 months & $2(4.55)$ & 84 & 11.31 & & \\
\hline 6 months & $4(9.09)$ & 77.75 & 9.03 & 3,40 & $\mathrm{~F}=.211^{\mathrm{NS}}$ \\
\hline 1 year & $4(9.09)$ & 79.5 & 11.24 & & \\
\hline more than 1year & $34(77.27)$ & 79.03 & 9.16 & & \\
\hline
\end{tabular}




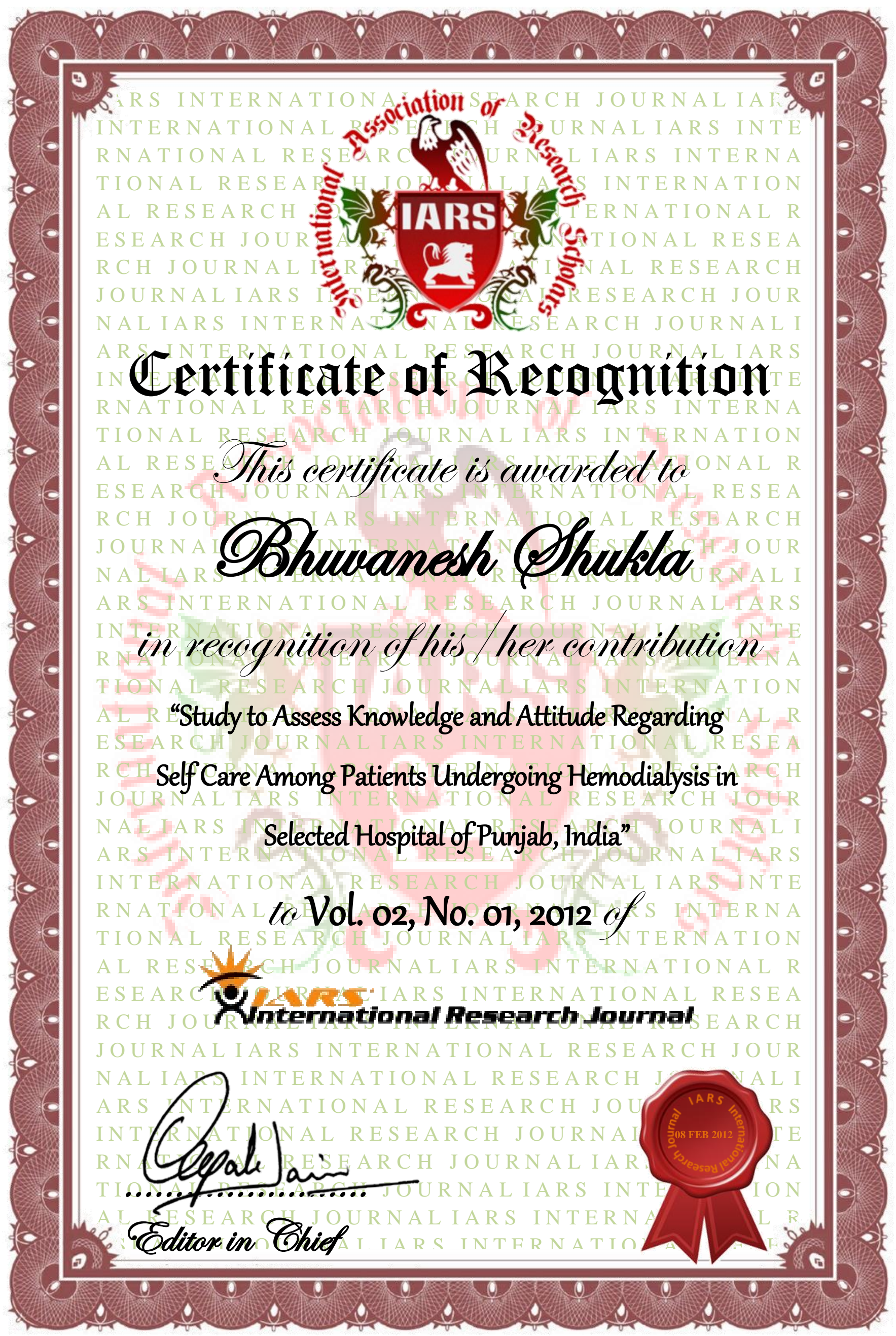




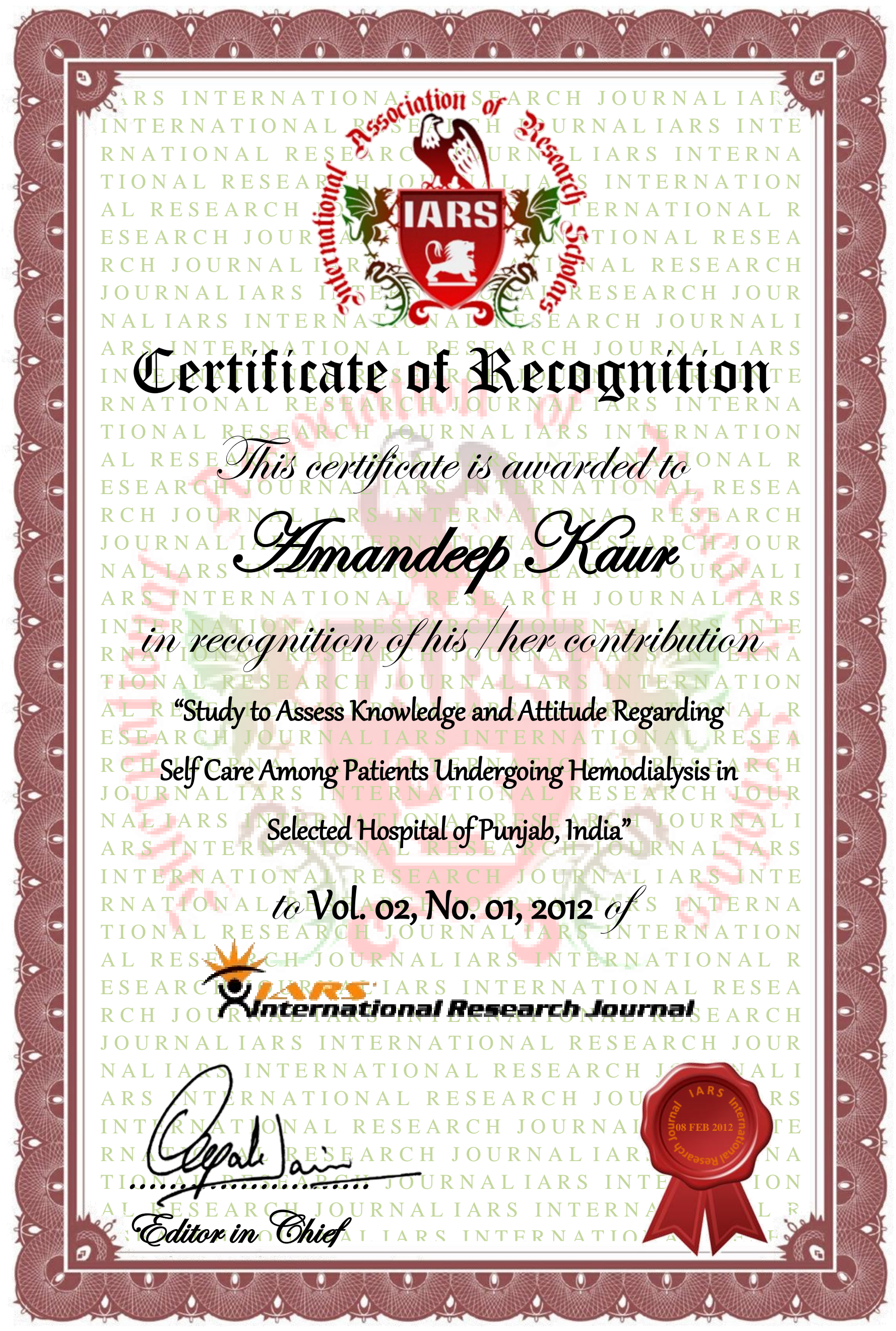

